\title{
Removal of Branched-Chain Amino Acids by Peritoneal Dialysis, Continuous Arteriovenous Hemofiltration, and Continuous Arteriovenous Hemodialysis in Rabbits: Implications for Maple Syrup Urine Disease Treatment
}

\author{
J. B. GOUYON, J. DESGRES, AND C. MOUSSON \\ Services de Pédiatrie 2 [J.B.G.], de Biochimie [J.D.], et de Néphrologie [C.MI.], Centre Hospitalier Universitaire, \\ 21034 Dijon Cedex, France
}

\begin{abstract}
Renal elimination of branched-chain amino acids (BCAA) is low in maple syrup urine disease, and peritoneal dialysis may be required in an emergency situation for removal of the three BCAA (leucine, isoleucine, and valine). However, failures of BCAA removal by peritoneal dialysis have been reported, especially in neonates. Therefore, we tested the ability of continuous hemofiltration and continuous hemodialysis to remove BCAA as compared with peritoneal dialysis. Experiments were conducted in 15 anesthetized adult rabbits infused with leucine, isoleucine, and valine. In group $1(n=7)$, peritoneal dialysis (dialysate $=75 \mathrm{~mL} / \mathrm{kg}$ ) and continuous arteriovenous hemofiltration with a polysulfone $800-\mathrm{cm}^{2}$ hemofilter were simultaneously performed during $\mathbf{4 0} \mathrm{min}$. In group 2 $(n=8)$, continuous arteriovenous hemofiltration and continuous arteriovenous hemodialysis were successively performed during $30 \mathrm{~min}$ in a randomly settled order. Animals had high and stable BCAA plasma levels during the experimental procedure. As compared with peritoneal dialysis, continuous arteriovenous hemofiltration constantly showed a significant increase in clearances of leucine $(+159$ $\pm 99 \%)$, isoleucine $(+176 \pm 107 \%)$, and valine $(+125 \pm$ $76 \%$ ). In comparison with continuous arteriovenous hemofiltration, continuous arteriovenous hemodialysis constantly showed significant increased values in clearances of leucine $(+90 \pm 43 \%)$, isoleucine $(+95 \pm 45 \%)$, and valine $(+99 \pm 52 \%)$. During continuous arteriovenous hemofiltration and continuous arteriovenous hemodialysis, a significant positive correlation was established between urea clearance and clearances of leucine $\left(r^{2}=0.953\right.$ and 0.927 , respectively), isoleucine $\left(r^{2}=0.948\right.$ and 0.910 , respectively), and valine $\left(r^{2}=0.953\right.$ and 0.864 , respectively). (Pediatr Res 35: 357-361, 1994)
\end{abstract}

\section{Abbreviations}

MSUD, maple syrup urine disease BCAA, branched-chain amino acid $P D$, peritoneal dialysis

CAVH, continuous arteriovenous hemofiltration

CAVHD, continuous arteriovenous hemodialysis

Received March 11, 1993; accepted October 7, 1993.

Correspondence and reprint requests: J. B. Gouyon, Service de Pediatrie 2, 10

Bd Maréchal de Lattre de Tassigny, 21034 Dijon Cedex, France.

Supported in part by a grant from Nephro System Lab.
MSUD is an organic aciduria caused by an inherited deficiency of branched-chain 2-keto acid dehydrogenase, resulting in a marked increase in plasma and cerebrospinal fluid concentrations of all three BCAA and branched-chain 2-keto acids (1). Extremely elevated concentrations of these neurotoxic compounds (mainly leucine and 2-keto isocaproic acid) are frequently observed in blood and cerebrospinal fluid in neonates either at the moment of initial diagnosis of classic MSUD or later during reduced caloric intake or acute intercurrent illness. Renal elemination of BCAA is low in MSUD (2), and multiple exchange transfusions or PD may be required in an emergency, with a high energy intake and a free BCAA diet (2-8). A 24-h PD is usually sufficient to reduce plasma leucine levels (2). Nevertheless, failures of BCAA removal by $\mathrm{PD}$ have been reported, probably as a result of concurrent severe catabolism, inadequate splanchnic blood flow, or technical difficulties $(2,6,9)$. Recently, continuous hemofiltration was shown to reduce rapidly $\mathrm{BCAA}$ blood levels in three neonates with MSUD (10-12). Hemofiltration removes nonprotein-bound low-weight molecules by an ultrafiltration mechanism, and this procedure has been used previously as a simple, safe, and effective treatment in fluidoverloaded infants and neonates with acute kidney failure (13). The basic hemofiltration procedure has been recently modified by instilling dialysate in the ultrafiltrate compartment. This new epurative method, called continuous hemodialysis, combines the convective transport of hemofiltration with the diffusive transport of hemodialysis, thus leading to a marked improvement in solute removal (urea particularly) (14). CAVHD and continuous venovenous hemodialysis are effective means for renal replacement therapy in neonates and infants, especially when an hypercatabolic state is associated $(15,16)$.

Because BCAA are low-weight molecules, we hypothesized that continuous hemofiltration and continuous hemodialysis may be valuable for BCAA removal. The lack of previous comparative data on BCAA removal by $\mathrm{PD}$, continuous hemofiltration, and continuous hemodialysis led to the development of an experimental animal model allowing the comparison of these procedures.

\section{MATERIALS AND METHODS}

Experiments were performed on 15 adult male New Zealand White rabbits weighing 2430 to $2990 \mathrm{~g}$ that were fasted for $24 \mathrm{~h}$. Five additional animals allowed for the assessment of plasma amino acids physiologic profile in rabbits.

Animal Preparation. Animals were anesthetized with $30 \mathrm{mg} /$ $\mathrm{kg}$ sodium pentobarbital infused in a peripheral vein. Supplementary doses were given therefore as required to maintain a 
surgical level of anesthesia. Tracheal cannulation allowed mechanical ventilation (Harvard Apparatus respirator, Harvard Apparatus Co., Millis, MA). A $100 \mathrm{mg} / \mathrm{kg}$ vecuronium dose was administered during vascular catheterization. For vascular access, the left carotid artery was cannulated with an 18-gauge, 44$\mathrm{mm}$ catheter (Cathlon IV G18, Critikon, Chatenay-Malabry, France) and the right external jugular vein with a 4-Fr 110-mm catheter (Seldicath $1.3 \mathrm{~mm}$, Plastimed, St-Leu-la-Forêt, France). Moreover, a polyethylene catheter (Trocar catheter, Argyle, Morangis, France) was surgically inserted in the peritoneal cavity at the midline of the abdominal wall in seven animals (group 1).

A total of $40 \mathrm{~min}$ was spent for the surgical procedure, and a loading dose of urea $(20 \mathrm{mmol} / \mathrm{kg})$, L-leucine $(4000 \mu \mathrm{mol}), \mathrm{L}$ isoleucine $(800 \mu \mathrm{mol})$, and L-valine $(800 \mu \mathrm{mol})$ was infused at the end of the surgical preparation. A maintenance dose of urea $(2 \mathrm{mmol} / \mathrm{kg} / \mathrm{h})$, L-leucine $(6000 \mu \mathrm{mol} / \mathrm{h})$, L-isoleucine $(1200$ $\mu \mathrm{mol} / \mathrm{h})$, and $\mathrm{L}$-valine $(1200 \mu \mathrm{mol} / \mathrm{h})$ was mandatory to avoid a rapid decline in BCAA plasma concentrations. Loading and hourly maintenance doses were diluted in $40 \mathrm{~mL}$ and $60 \mathrm{~mL}$ of isotonic saline solute, respectively, and infused in a peripheral vein. A 30-min equilibration period followed these procedures and preceded the onset of the experimental protocols.

Body temperature was kept constant at $38.5-39^{\circ} \mathrm{C}$ with a warming operating table (17). Throughout the experiment, mean arterial pressure was continuously recorded (Hewlett Packard, model 78354 A, Palo Alto, CA). To avoid blood pressure fluctuations and peritoneal hypoperfusion in group 1, we took care to preserve arterial blood pressure stability. Therefore, withdrawing of each blood sample was followed by an immediate infusion of the same volume of an isotonic gelatine solute (Plasmion, Roger Bellon Lab., Neuilly-sur-Seine, France).

Experimental Protocols. Group $1(n=7)$. PD and CAVH were simultaneously performed over a 40 -min period to obtain similar experimental conditions (namely, systemic hemodynamics, hematocrit, arterial oncotic pressure, and BCAA blood levels) for these two procedures.

A commercially available dialysate solution [glucose $(83$ $\mathrm{mmol} / \mathrm{L})$, sodium ( $145 \mathrm{mmol} / \mathrm{L})$, bicarbonate $(45 \mathrm{mmol} / \mathrm{L})$, and choride $(102 \mathrm{mmol} / \mathrm{L})]$ was warmed to $37^{\circ} \mathrm{C}$, and a $75 \mathrm{~mL} / \mathrm{kg}$ dose was peritoneally infused after the equilibration period. Dialysate was left in the peritoneal cavity for $40 \mathrm{~min}$. Instillation and dialysate return took approximately 3 and $5 \mathrm{~min}$, respectively. Drainage fluid did not show macroscopic blood contamination.

CAVH started as soon as the dialysate was instillated in the peritoneal cavity for PD. CAVH (Fig. 1) was achieved with an $800-\mathrm{cm}^{2}$ polysulfone hemofilter (Minifilter Plus, Amicon, Danvers, MA). Lines connected the hemofilter with the arterial and venous catheters, and the extracorporeal volume was $15 \mathrm{~mL}$. The arterial line allowed blood pressure recording and prefilter blood samplings, whereas the venous line allowed postfilter blood samplings.

Hemofilters were filled with heparinized (5000 IU/L) isotonic saline solution according to the manufacturer's recommendations. Heparin (loading dose, $200 \mathrm{IU} / \mathrm{kg}$; maintenance dose, 20 $\mathrm{IU} / \mathrm{kg} / \mathrm{h}$ ) was used as an antithrombotic agent to prevent hemofilter clotting. No hemofilter showed fiber clotting at the end of the experiment.

Ultrafiltrate was drained by a $105-\mathrm{cm}$ tube in a preweighed bag. Ultrafiltrate was totally replaced by infusion of a substitution fluid, which included the isotonic vehicle for BCAA infusion and consisted of sodium chloride $(123 \mathrm{mmol} / \mathrm{L})$, potassium chloride $(4 \mathrm{mmol} / \mathrm{L})$, sodium bicarbonate $(30 \mathrm{mmol} / \mathrm{L})$, and glucose $(8.3$ $\mathrm{mmol} / \mathrm{L})$.

Arterial blood samplings were performed at the 1st, 20th, and 40th min. Amino acids and urea concentrations, hematocrit, bicarbonates, oncotic pressure $(\pi)$, oxygen saturation, and $\mathrm{pH}$ were measured in each arterial blood sample. Amino acids and urea concentrations were also determined in peritoneal dialysate and ultrafiltrate. Hematocrit was also measured in venous blood samples at the 20th and 40th min.

Group $2(n=8)$. Rabbits were successively submitted to CAVH and CAVHD (Fig. 1) in a randomly settled order. Each procedure lasted $30 \mathrm{~min}$. CAVH was performed as in group 1. During CAVHD, a $1000 \mathrm{~mL} / \mathrm{h}$ dialysate flow was obtained with a peristaltic pump (VM $8000 \mathrm{~m}$, Vial Medical, St-Martin-LeVinoux, France). The dialysate composition was similar to the substitution fluid, and the ultrafiltrate and dialysate fluids were collected together in the collecting bag.

Arterial blood samplings were performed at the 1st, 15th, and 30 th min of each 30 -min period. Amino acids and urea concentrations and hematocrit, bicarbonates, oncotic pressure, oxygen saturation, and $\mathrm{pH}$ values were determined in each arterial blood sample. Amino acids and urea concentrations were also measured in collected solutes.

Analytical Methods. During CAVH, the ultrafiltrate volume was calculated from the change in weight of preweighed bags without specific gravity correction (E5500-S-F2 scale, Sartorius, Gottingen, Germany). During CAVHD, the ultrafiltrate volume was calculated by subtracting the infused dialysate from the collected fluid. During PD, the dialysate volume was assumed to be the infused volume $(75 \mathrm{~mL} / \mathrm{kg})$.

Amino acids were analyzed by column chromatography on an amino acid analyzer (System 6300, high-performance analyzer, Beckman, Palo Alto, CA). The analysis of urea, $\pi$, and arterial gas were performed with an Astra-8 analyzer (Beckman, Brea, CA), an Oncometer Osmomat 050 (Gonatec, Berlin, Germany), and $\mathrm{pH} / \mathrm{blood}$ gas analyzer 168 (Ciba Corning, Milfield, MA), respectively.

Data Analysis. The clearance rate (C) and sieving coefficient (SC) were measured for urea, leucine, isoleucine, and valine. SC of a solute is the ratio of peritoneal dialysate or ultrafiltrate concentrations to plasma concentrations. $\mathrm{SC}$ and $\mathrm{C}$ for peritoneal dialysis $\left(\mathrm{SC}_{\mathrm{PD}}, \mathrm{C}_{\mathrm{PD}}\right), \mathrm{SC}$ and $\mathrm{C}$ for $\mathrm{CAVH}$ (SC $\left.\mathrm{SAVH}_{\mathrm{CA}}, \mathrm{C}_{\mathrm{CAVH}}\right), \mathrm{C}$ for CAVHD $\left(\mathrm{C}_{\mathrm{CAVHD}}\right)$, blood flow $(\mathrm{Qb})$, plasma flow $(\mathrm{Qp})$, and filtration fraction (FF) were calculated from the following standard equations:

$$
\begin{gathered}
\mathrm{Qb}=(\mathrm{Qf} \times \mathrm{Hct} \mathrm{o}) /(\mathrm{Hct} \mathrm{o}-\mathrm{Hct} \mathrm{i}) \\
\mathrm{Qp}=\mathrm{Qb} \times(1-\mathrm{Hct} \mathrm{i} / 100)
\end{gathered}
$$

where $\mathrm{Qf}=$ ultrafiltrate rate and Hct $\mathrm{i}$ and Hct $\mathrm{o}=$ hematocrit at the inlet and outlet of the hemofilter;

$$
\mathrm{FF}=\mathrm{Qf} / \mathrm{Qp}
$$

$\mathrm{SC}_{\mathrm{PD}}=$ concentration of solute in the peritoneal dialysate fluid/ mean concentration of solute in arterial plasma

$\mathrm{SC}_{\mathrm{CAVH}}=$ concentration of solute in the ultrafiltrate fluid/ mean concentration of solute in arterial plasma

$\mathrm{C}_{\mathrm{PD}}=\mathrm{SC}_{\mathrm{PD}} \times$ peritoneal dialysate volume $/ \mathrm{PD}$ duration

$$
\begin{gathered}
\mathrm{C}_{\mathrm{CAVH}}=\mathrm{SC}_{\mathrm{CAVH}} \times \mathrm{Qf} \\
\mathrm{C}_{\text {CAVHD }}=\mathrm{U} \times \mathrm{V} / \mathrm{P}
\end{gathered}
$$

where $\mathrm{U}=$ solute concentration in fluid drained in the collecting apparatus, $\mathrm{V}=$ rate $(\mathrm{mL} / \mathrm{min})$ of fluid drained in the collecting apparatus, and $\mathrm{P}=$ mean plasma solute concentration during the CAVHD period.

Effect of time on physiologic parameters and BCAA plasma levels was assessed within each group by the two-way analysis of variance with unreplicated block design. Wilcoxon's signed-rank test was used for comparisons of procedures efficiencies within each group (i.e. sieving coefficients; BCAA and urea clearances). The urea and BCAA clearances were correlated by linear regression. The level of statistical significance was 0.05 . Values were expressed as means $\pm \mathrm{SD}$. 


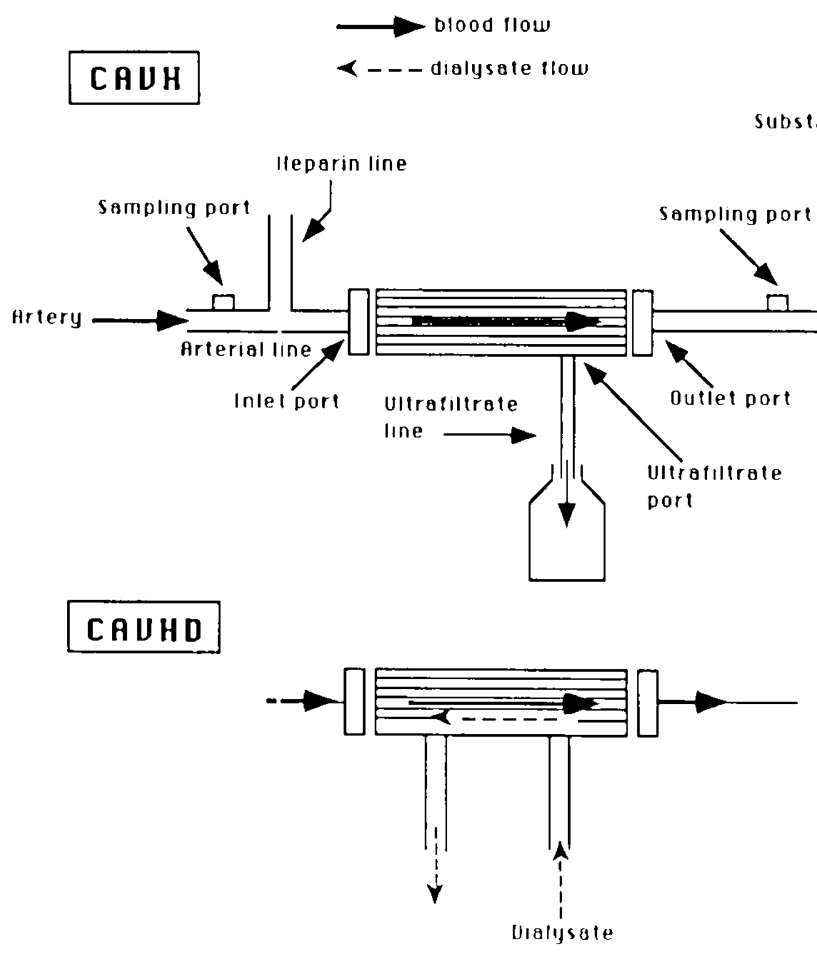

Fig. 1. CAVH and CAVHD.

\section{RESULTS}

Plasma amino acid composition was determined in five control anesthetized rabbits before any solute administration. Mean leucine, isoleucine, and valine plasma levels were $138 \mu \mathrm{mol} / \mathrm{L}$ (range, 95-181), $75 \mu \mathrm{mol} / \mathrm{L}$ (range, 45-83), and $225 \mu \mathrm{mol} / \mathrm{L}$ (range, 150-262), respectively. These values were close to BCAA plasma levels recorded in normal infants (18).

Group 1. Table 1 indicates the mean values for physiologic parameters during the experimental procedure. Mean arterial blood pressure, arterial oxygen saturation, bicarbonates, and $\mathrm{pH}$ did not vary significantly throughout the experiments. At the end of the experiment arterial oncotic pressure, hematocrit value, and body temperature fell slightly but significantly by $11.8 \pm$ $6.9 \%, 11.3 \pm 4.8 \%$, and $0.33 \pm 0.16^{\circ} \mathrm{C}$, respectively. However,

Table 1. Physiologic parameters, BCAA, and urea plasma levels at the onset, midpoint, and end of the experiment in seven rabbits (group 1 )*

\begin{tabular}{lccc}
\hline \multicolumn{1}{c}{ Parameters } & Onset & Midpoint & End \\
\hline $\begin{array}{l}\text { Mean arterial blood } \\
\text { pressure (mm Hg) }\end{array}$ & $74.8 \pm 15.3$ & $72.6 \pm 6.4$ & $64.0 \pm 5.7 \dagger$ \\
$\begin{array}{c}\text { Body temperature } \\
\left({ }^{\circ} \mathrm{C}\right)\end{array}$ & $39.5 \pm 0.7$ & $39.1 \pm 0.6$ & $38.8 \pm 0.5 \ddagger$ \\
Hematocrit (\%) & $38 \pm 2$ & $39 \pm 2$ & $37 \pm 5 \ddagger$ \\
Arterial oncotic & $15.9 \pm 3.1$ & $16.7 \pm 3.6$ & $15.4 \pm 3.3 \ddagger$ \\
$\quad$ pressure (mm Hg) & & & \\
$\begin{array}{l}\text { Oxygen saturation } \\
\quad \%)\end{array}$ & $97.5 \pm 2.8$ & $99.4 \pm 0.3$ & $99.5 \pm 0.3 \dagger$ \\
Arterial pH & $7.27 \pm 0.07$ & $7.31 \pm 0.09$ & $7.36 \pm 0.13 \dagger$ \\
Arterial bicarbonates & $23.3 \pm 3.4$ & $20.2 \pm 4.4$ & $20.5 \pm 5.9 \dagger$ \\
$\quad($ mmol/L) & & & \\
Leucine $(\mu \mathrm{mol} / \mathrm{L})$ & $2746 \pm 1505$ & $2827 \pm 1332$ & $3021 \pm 715 \dagger$ \\
Isoleucine $(\mu \mathrm{mol} / \mathrm{L})$ & $519 \pm 271$ & $610 \pm 293$ & $597 \pm 208 \dagger$ \\
Valine $(\mu \mathrm{mol} / \mathrm{L})$ & $748 \pm 277$ & $880 \pm 342$ & $904 \pm 227 \dagger$ \\
Urea $(\mathrm{mmol} / \mathrm{L})$ & $26.4 \pm 1.7$ & $25.1 \pm 1.8$ & $26.1 \pm 3.7 \dagger$ \\
\hline
\end{tabular}

*Values are means $\pm \mathrm{SD}$.

$\dagger$ No significant $(p>0.05)$ changes during the experimental period. $\ddagger$ Significant $(p<0.05)$ changes during the experimental period. the body temperature remained in a physiologic range (17). Hematocrit value fell slightly, albeit significantly, probably because of repeated blood samplings.

The loading and maintenance doses of leucine, isoleucine, valine, and urea allowed stable plasma values for the three BCAA and urea (Table 1). Mean values for blood and plasma flow, filtration fraction, and ultrafiltrate rate during $\mathrm{CAVH}$ were 8.2 $\pm 4.0 \mathrm{~mL} / \mathrm{min}$ (range, $5.6-16.8$ ), $5.2 \pm 2.5 \mathrm{~mL} / \mathrm{min}$ (range, $3.4-$ 10.6), $0.368 \pm 0.065 \mathrm{~mL} / \mathrm{min}$ (range, $0.290-0.474$ ), and $1.82 \pm$ $0.60 \mathrm{~mL} / \mathrm{min}$ (range, $1.26-3.08$ ), respectively.

The arterial concentrations used for BCAA and urea sieving coefficient calculations were individually obtained by averaging the values obtained at the onset, midpoint, and end of the experimental protocol. The sieving coefficients for leucine, isoleucine, valine, and urea were significantly $(p<0.05)$ higher with CAVH as compared with PD: $1.034 \pm 0.193$ versus 0.159 $\pm 0.069 ; 1.019 \pm 0.178$ versus $0.147 \pm 0.061,1.017 \pm 0.123$ versus $0.174 \pm 0.063$, and $1.02 \pm 0.02$ versus $0.29 \pm 0.10$, respectively.

As compared with PD, CAVH also allowed significantly higher clearances for leucine, isoleucine, valine, and urea (Table 2). Noteworthy is that the increase in BCAA clearances was constantly observed. As compared with $\mathrm{PD}, \mathrm{CAVH}$ increased the clearances of leucine, isoleucine, and valine by $+159 \pm 99 \%$ (range, +81 to $+372 \%),+176 \pm 107 \%(+89$ to $+407 \%)$, and $+125 \pm 76 \%$ ( +60 to $+281 \%$ ), respectively.

$\mathrm{CAVH}$ was characterized by a significant positive correlation

Table 2. BCAA and urea clearances ( $\mathrm{mL} / \mathrm{min}$ ) obtained by CAVH and $P D$ in seven rabbits (group 1)*

\begin{tabular}{lcc}
\hline & CAVH & PD \\
\hline Leucine & $1.87 \pm 0.62$ & $0.74 \pm 0.16 \dagger$ \\
Isoleucine & $1.85 \pm 0.63$ & $0.69 \pm 0.16 \dagger$ \\
Valine & $1.84 \pm 0.60$ & $0.83 \pm 0.15 \dagger$ \\
Urea & $1.84 \pm 0.60$ & $1.40 \pm 0.23 \dagger$ \\
\hline
\end{tabular}

* Values are means $\pm \mathrm{SD}$.

+ Significant $(p<0.05)$ changes when the CAVH and PD periods were compared. 
between urea clearance and clearances of leucine $\left(r^{2}=0.797\right)$, isoleucine $\left(r^{2}=0.826\right)$, and valine $\left(r^{2}=0.911\right)$.

Group 2. Table 3 indicates the mean values for experimental parameters measured during $\mathrm{CAVH}$ and CAVHD periods. Mean blood pressure, body temperature, hematocrit, oncotic pressure, arterial oxygen saturation, $\mathrm{pH}$ and bicarbonates, BCAA, and urea blood levels were similar during CAVH and CAVHD.

Mean values for ultrafiltrate rate during CAVH and CAVHD were $1.87 \pm 0.53$ and $3.28 \pm 1.6 \mathrm{~mL} / \mathrm{min}$, respectively, but this difference did not reach statistical significance.

As compared with CAVH, CAVHD allowed a constant and significant increase in clearances of BCAA and urea (Table 4) and increased the clearances of leucine, isoleucine, valine, and urea by $+90 \pm 43 \%$ (range, +14 to $+142 \%$ ), $+95 \pm 45 \%$ (range, +19 to $+162 \%),+99 \pm 52 \%$ (range, +16 to $+186 \%$ ), and +118 $\pm 43 \%$ (range, +38 to $+162 \%$ ), respectively.

During CAVH and CAVHD, a significant positive correlation was established between urea clearance and clearances of leucine ( $r^{2}=0.953$ and 0.927 , respectively), isoleucine $\left(r^{2}=0.948\right.$ and 0.910 , respectively), and valine $\left(r^{2}=0.953\right.$ and 0.864 , respectively).

\section{DISCUSSION}

Experimental model. Our study suggests that this experimental animal model is valuable for the comparison of $\mathrm{PD}, \mathrm{CAVH}$, and CAVHD in MSUD because of the results discussed below.

BCAA plasma levels in normal adult rabbits were close to values recorded in infants (18), thus giving the possibility to reproduce amino acid blood profile of MSUD by infusion of BCAA. High leucine, isoleucine, and valine blood levels obtained in BCAA-infused rabbits were in the range of values observed in neonates with MSUD who required $\operatorname{PD}(2,3,5)$.

The stability of experimental conditions was mandatory for the comparison of PD, CAVH, and CAVHD efficiencies. In both groups, BCAA blood levels and main physiologic conditions

Table 3. Physiologic parameters, BCAA, and urea plasma levels during $C A V I I$ and $C A V H D$ in eight rabbits (group 2)*

\begin{tabular}{lcc}
\hline \multicolumn{1}{c}{ Parameters } & CAVH & CAVHD \\
\hline $\begin{array}{l}\text { Mean arterial blood pres- } \\
\quad \text { sure }(\mathrm{mm} \mathrm{Hg})\end{array}$ & $70.0 \pm 18.5$ & $66.7 \pm 16.6 \dagger$ \\
Body temperature $\left({ }^{\circ} \mathrm{C}\right)$ & $39.2 \pm 1.2$ & $39.5 \pm 1.0 \dagger$ \\
Hematocrit $(\%)$ & $35 \pm 7$ & $35 \pm 6 \dagger$ \\
Oncotic pressure $(\mathrm{mm} \mathrm{Hg})$ & $18.3 \pm 3.7$ & $17.6 \pm 3.1 \dagger$ \\
Oxygen saturation $(\%)$ & $99.6 \pm 0.15$ & $99.6 \pm 0.10 \dagger$ \\
Arterial pH & $7.45 \pm 0.16$ & $7.43 \pm 0.13 \dagger$ \\
Arterial bicarbonates & $20.3 \pm 4.2$ & $19.6 \pm 6.3 \dagger$ \\
$\quad$ (mmol/L) & $3438 \pm 1011$ & $3519 \pm 1271 \dagger$ \\
Leucine $(\mu \mathrm{mol} / \mathrm{L})$ & $763 \pm 213$ & $779 \pm 274 \dagger$ \\
Isoleucine $(\mu \mathrm{mol} / \mathrm{L})$ & $992 \pm 278$ & $1012 \pm 361 \dagger$ \\
Valine $(\mu \mathrm{mol} / \mathrm{L})$ & $23.9 \pm 4.0$ & $24.9 \pm 3.7 \dagger$ \\
Urea $(\mathrm{mmol} / \mathrm{L})$ &
\end{tabular}

* Values are means \pm SD. Individual values were obtained by averaging results recorded at the onset, midpoint, and end of each period.

$\dagger$ No significant $(p>0.05)$ difference when the CAVII and CAVHD periods were compared.

Table 4. BCAA and urea clearances ( $\mathrm{mL} / \mathrm{min}$ ) obtained by CAVH and CAVHD*

\begin{tabular}{lcc}
\hline & CAVH & CAVHD \\
\hline Leucine & $1.83 \pm 0.53$ & $3.45 \pm 1.13 \dagger$ \\
Isoleucine & $1.82 \pm 0.53$ & $3.49 \pm 1.14 \dagger$ \\
Valine & $1.83 \pm 0.54$ & $3.61 \pm 1.24 \dagger$ \\
Urea & $1.88 \pm 0.55$ & $4.04 \pm 1.29 \dagger$ \\
\hline
\end{tabular}

* Values are means \pm SD.

$\dagger$ Significant difference $(p<0.05)$ when the CAVH and CAVHD periods were compared. (arterial blood pressure, oxygen saturation, bicarbonates, and $\mathrm{pH})$ were stable during the experiments or remained in a physiologic range (body temperature). A slight decrease in body temperature, hematocrit value, and oncotic pressure was only observed when PD was compared with CAVH (group 1). Nevertheless, these changes could not be regarded as confusing factors because these two procedures were performed simultaneously.

The rabbit model allowed the assessment of hemofilters with filtration surface already used in human neonates with acute kidney failure (19). Values obtained during CAVH for blood flow, plasma flow, and ultrafiltration rate were comparable with that recorded in neonates treated for acute kidney failure by continuous venovenous hemofiltration or CAVH $(11,20)$.

The clearances obtained by PD for leucine, isoleucine, and valine in these adult rabbits $(0.74 \pm 0.16,0.69 \pm 0.16$, and 0.83 $\pm 0.15 \mathrm{~mL} / \mathrm{min}$, respectively) were close to values observed in human neonates by Saudubray et al. (2) (leucine, $0.52 \mathrm{~mL} / \mathrm{min}$ ), Rey et al. (3) (leucine, 0.26 to $0.36 \mathrm{~mL} / \mathrm{kg} / \mathrm{min}$ ), and Harris (5) (leucine, $7.6 \mathrm{~mL} / \mathrm{min} / \mathrm{m}^{2}$; isoleucine, $6.4 \mathrm{~mL} / \mathrm{min} / \mathrm{m}^{2}$; valine, $7.1 \mathrm{~mL} / \mathrm{min} / \mathrm{m}^{2}$ ). Moreover, we also observed that the BCAA peritioneal clearances were $40-50 \%$ of urea clearance, as previously recorded in children $(4,7)$.

$P D$ versus CAVH (group 1). As expected, this study demonstrated that the sieving coefficient (i.e. the ratio of ultrafiltrate to plasma concentrations) was close to 1 during hemofiltration not only for urea but also for leucine, isoleucine, and valine. This finding fits in well with previous studies that stated that the convective transport of hemofiltration allows urea and electrolytes removal (namely, nonprotein-bound low-weight molecules), with ultrafiltrate solute concentration close to plasma concentration (21).

The CAVH performed with a $800-\mathrm{cm}^{2}$ polysulfone hemofilter designed for neonates allowed a marked and significant increase in BCAA clearances as compared with PD, namely, the reference procedure (leucine, $+159 \pm 99 \%$; isoleucine, $+176 \pm 107 \%$; valine, $+125 \pm 76 \%$ ). Recently, CAVH or continuous venovenous hemofiltration allowed a rapid decline in BCAA plasma levels in three neonates with MSUD (10-12). The BCAA clearance rate was approximately $8 \mathrm{~mL} / \mathrm{min}$ in a neonate treated with CAVH (10). Efficacy has also been reported for high-flow continuous venovenous hemofiltration when ultrafiltrate rate varied from 150 to $600 \mathrm{~mL} / \mathrm{h}(11,12)$. However, the comparison between hemofiltration and $\mathrm{PD}$ for $\mathrm{BCAA}$ removal has not been yet reported in children.

CAVH versus CAVHD (group 2). Continuous hemodialysis has been developed recently and has allowed higher solute clearances (especially urea) as compared with hemofiltration (21). CAVHD has already been performed in neonates and infants with acute kidney failure and hypercatabolic state when urea removal capability by $\mathrm{CAVH}$ was overcome $(15,16,21)$. CAVHD then allowed a 2- to 4-fold increase in urea clearances as compared with $\mathrm{CAVH}(15,16)$. In this study, CAVHD also increased the urea clearance by $118 \pm 43 \%$ and allowed a constant and significant increase in BCAA clearances as compared with CAVH. The mean clearance of leucine, the main neurotoxic $\mathrm{BCAA}$, increased significantly from $1.83 \pm 0.53$ to $3.45 \pm 1.13 \mathrm{~mL} / \mathrm{min}$. As compared with CAVH, CAVHD increased the clearances of leucine, isoleucine, and valine by +90 $\pm 43 \%,+95 \pm 45 \%$, and $+99 \pm 52 \%$, respectively. Moreover, BCAA clearances were positively correlated with urea clearances during both CAVH and CAVHD. Thus, the efficacy of BCAA removal could be simply evaluated from the urea clearance calculation during these procedures.

Possible clinical implications are suggested by these experimental data, mainly when PD fails or is contraindicated. Even if PD is usually found to be effective, Saudubray et al. (2) reported that PD failed in 2 of 16 neonates with MSUD. A decrease in $\mathrm{PD}$ efficiency was also observed in a child with very high BCAA plasma levels (7). Theoretically, other therapeutic choices for extracorporeal BCAA removal should include continuous he- 
mofiltration, continuous hemodialysis, and intermittent dialysis (22). Practically, continuous hemofiltration and continuous hemodialysis have always been regarded as well-tolerated procedures in children $(15,16,21)$. Indeed, these procedures did not induce major hemodynamic disturbances or osmolar shifts, conditions of potential value in a critically ill patient with cerebral edema during worsening MSUD (2). In other aspects, systemic hemodynamic side effects could prohibit intermittent hemodialysis in MSUD treatment even if this technique has proved to be effective on one neonate (22).

In conclusion, BCAA clearances were markedly improved by hemofiltration as compared with $\mathrm{PD}$ in rabbits. Continuous dialysis proved to be superior to continuous hemofiltration for BCAA removal. Further studies are mandatory to set up the definitive benefits of continuous hemofiltration and continuous hemodialysis in MSUD in comparison with PD.

Acknowledgments. The authors thank N. Wittig, O. Champeil, M. C. Pillot, V. Roblot, and B. Gouyon for skillful technical assistance. We acknowledge Dr. D. Semama for judicious advice.

\section{REFERENCES}

1. Dancis J, Levitz M, Westall R 1960 Maple syrup urine disease: branched-chain ketoaciduria. Pediatrics 25:72-79

2. Saudubray JM, Ogier H, Charpentier C, Depondt E, Coude FX, Munnich A Mitchell G, Rey F, Rey J, Frezal J 1984 Neonatal management of organic acidurias. Clinical update. $J$ Inherit Metab Dis 7:2-9

3. Rey F, Rey J, Cloup M, Feron JF, Dore R, Labrune B, Frezal J 1969 Traitement d'urgence d'une forme aigue de leucinose par dialyse péritonéale. Arch $\mathrm{Fr}$ Pediatr 26:133-137

4. Gaull G 1969 Pathogenesis of maple syrup urine disease: observations during dietary management and treatment of coma by peritoneal dialysis. Biochem Med 3:130-149

5. Harris RJ 1971 Infection in maple syrup urine disease. Lancet 2:813-814

6. Saudubray JM, Fournet JP, Cloup M 1971 Intérêt de la dialyse péritonéale dans le traitement d'urgence des maladies métaboliques d'origine constitutionnelle révélées dans la période néo-natale. Ann Med Intern (Paris) 122:1279-1283
7. Wendel U, Becker K. Przyrembel H, Bulla M, Manegold C, Mench-Hoinowxki A, Langenbeck U 1980 Peritoneal dialysis in maple syrup urine disease: studies on branched-chain amino and keto-acids. Eur J Pediatr 134:57-63

8. Saudubray JM, Ogier $H$, Billette de Vilmeur $T$, Bonnefont JP, Lyonnet $S$ Herve F, Munnich A. Rabier D. Coude M. Charpentier C 1991 Inborn errors of the metabolism of branched-chain amino acids. In: Schaub J, Van Hoof F, Vis HL (eds) Inborn Errors of Metabolism. Nestlé Nutrition Workshop Series, Vol 24. Raven Press, New York, pp 137-153

9. Fine RN 1982 Peritoneal dialysis update. J Pediatr 100:1-7

10. Ring E, Zobel G. Stocker S 1990 Clearance of toxic metabolites during therapy for inborn errors of metabolism. J Pediatr 117:349-350

11. Thompson GN, Butt WW Shann FA. Kirby DM, Henning RD, Howells DW Osborne A 1991 Continuous venovenous hemofiltration in the management of acute decompensation in inborn errors of metabolism. J Pediatr 118:879884

12. Casadevall I, Ogier H, Germain JF, Daoud P. Hartmann JF, Mercier JC, Beaufils F 1992 Hemofiltration artérioveineuse continue. Prise en charge en cas d'une leucinose néonatale. Arch Fr Pediatr 49:803-805

13. Lieberman KV 1987 Continuous arteriovenous hemofiltration in children. Pediatr Nephrol 1:330-338

14. Geronemus R, Schneider N 1984 Continuous arteriovenous hemodialysis: a new modality for treatment of acute renal failure. Trans Am Soc Artif Intern Organs 30:610-614

15. Zobel G, Ring E, Trop M, Stein JL 1986 Arteriovenous hemofiltration in children. Int J Pediatr Nephrol 7:203-206

16. Bishof NA, Welch TR, Strife F, Ryckman FC 1990 Continuous hemodiafiltration in children. Pediatrics 85:819-823

17. Kaplan HM, Timmons ED 1979 Rabbit data and essential procedures. In Kaplan HM, Timmons ED (eds) The Rabbit. A Model for the Principles of Mammalian Physiology and Surgery. Academic Press. New York, pp 3-12

18. Kamoun P, Parvy P, Ravier D 1991 Indication et interpretation de la chromatographie des acides aminés pour le diagnostic des maladies métaboliques. In: Saudubray A (ed) Progrés en Pédiatrie. Maladies Métaboliques. Doin Editeurs, Paris, pp 1-12

19. Bambauer R, Jutzler GA, Philippi H, Jesberger HJ, Limbach HG, Richter J Sitzmann FC, Pieroth $W 1988$ Hemofiltration and plasmapheresis in premature infants and newborns. Artif Organs 12:20-26

20. Ronco C, Brendolan A. Bragantini L, Chiaramonte S. Feriani M, Fabris A Dell'Aquila R. La Greca G 1986 Treatment of acute renal failure in newborns by continuous arterio-venous hemofiltration. Kidney Int 29:908-915

21. Paganini EP 1987 Continuous renal prosthetic therapy in acute renal failure: an overview. Pediatr Clin North Am. 34:165-185

22. Rutledge SL, Havens PL. Haymond MW, McLean RH, Kan JS, Brusilow SW 1990 Neonatal hemodialysis: effective therapy for the encephalopathy of inborn errors of metabolism. J Pediatr 116:125-128 